\title{
Point-of-View: Arguments for conventional fisheries management and against no-take marine protected areas: only half of the story?
}

\author{
P. J. S. Jones
}

Received: 24 July 2006/ Accepted: 29 September 2006/ Published online: 8 November 2006

(C) Springer Science+Business Media B.V. 2006

\begin{abstract}
Recent arguments for conventional fisheries management approaches (CFMAs) and against no-take marine protected areas (NTMPAs) are reviewed, i.e. CFMAs are more effective, density-dependent factors will lead to reduced fish stock production in and around NTMPAs, rights-based approaches in combination with CFMAs will be more effective, and natural refuges from fishing already exist. It is concluded that these are largely valid but only from a fisheries management perspective. The arguments of proponents of NTMPAs and those of proponents of CFMAs are considered as contrasting storylines, the divergences between which are based on two key factors: different objectives and different science. In relation to different objectives, it is concluded that the arguments against NTMPAs based on their lack of fisheries management benefits must be considered as only applying to the secondary resource conservation objectives of such designations and not to the primary marine biodiversity conservation objectives. On this basis it is argued that it is counter-productive for NTMPAs to be 'sold' on a
\end{abstract}

P. J. S. Jones $(\bowtie)$

Environment and Society Research Unit (ESRU),

Department of Geography, University College

London (UCL), Pearson Building, London WC1E 6BT, UK

e-mail: p.j.jones@ucl.ac.uk win-win basis, including their potential to deliver fisheries management benefits, as this detracts from their marine biodiversity conservation objectives and leaves such calls open to arguments that CFMAs are better able to deliver fisheries management objectives. In relation to different science, it is concluded that criticisms of NTMPAs and support for CFMAs implicitly resist the shift from Mode 1 (reductive, intradisciplinary) to Mode 2 (holistic, trans-disciplinary) science that is inherent in calls for NTMPAs as part of an ecosystem approach. Mode 2 science attempts to accommodate both uncertainty and wider societal values and preferences, and it is argued that arguments for NTMPAs should be more explicitly focussed on this potential. It is difficult, if not impossible and inappropriate, to extend the reductive approach inherent in CFMA analyses to encompass the broader ethical and scientific concerns for the health of marine ecosystems and their component populations and habitats that arguments for NTMPAs reflect. NTMPA proponents might focus on stressing that arguments against such designations and in favour of CFMAs do not encompass such valid concerns, therefore they tell only half of the story.

Keywords Ecosystem approach · Fisheries management - Marine protected areas - Mode 2 science 


\section{Introduction}

This paper reviews arguments for conventional fisheries management approaches (CFMAs) and against no-take marine protected areas (NTMPAs). It is set against a background of both many calls for NTMPAs and increasing arguments that such calls are 'red herrings' as they distract attention from the real fisheries management issues (Kaiser 2005). It is based on the alternative argument that NTMPAs may not be a fisheries panacea but nor are they a red herring, as they reflect the extension of scientific and ethical concerns for the wider health of marine ecosystems, including their component populations and habitats, the processes that sustain them and the functions they provide.

The paper begins with a review of some international calls for NTMPAs and then considers some recent challenges to the potential of such designations, i.e. that CFMAs are more effective, density-dependent factors will lead to reduced fish stock production in and around NTMPAs, rights-based approaches in combination with CFMAs will be more effective, and natural refuges from fishing already exist. The 'storylines' behind these challenges, arguing mainly for CFMAs, are contrasted with those behind challenges to CFMAs, arguing mainly for NTMPAs. The divergences between these storylines are considered in terms of whether they represent different objectives and different science.

\section{International developments}

No-take marine protected areas can be defined as marine areas in which the extraction of living and non-living resources is permanently prohibited, except as necessary for monitoring or research to evaluate effectiveness (NRC 2001). As such they are the most restrictive type of marine protected area, this being a general term for a wide variety of designations which confer varying degrees and types of protection. NTMPAs are thus equivalent to Category Ia (strict nature reserve) under the IUCN's protected area management categories (IUCN 1994). A wide variety of terms is used to describe them, e.g. marine reserves, no-take zones/reserves, highly protected marine areas, marine preservation zone, scientific zone, but this paper will employ the generic term 'no-take marine protected area' (NTMPA).

There has been a rapidly growing interest in recent years in the potential of NTMPAs as a partial solution to declines in both marine biodiversity $^{1}$ and fish stocks, as part of an ecosystem approach. The increasing number of publications on various aspects of NTMPAs (Willis et al. 2003) reflects this interest. Jones (2006) reviews over 40 publications which argue for NTMPAs by reporting (a) the impacts of fishing on species, habitats and ecosystems and the need for restoration; (b) the potential benefits of NTMPAs based on models and (c) the observed effectiveness of NTMPAs in providing for the recovery of fish populations within and beyond their boundaries, whilst a recent UK report cited over 300 such papers (RCEP 2004).

There have also been calls from the international scientific community for the further designation of NTMPAs. In 1998, 1,605 marine scientists endorsed a call for governments to protect $20 \%$ of the world's seas from threats by 2020 (MCBI 1998). Similarly, in 2001, 161 marine scientists endorsed a scientific consensus statement calling for a network of NTMPAs to conserve marine biodiversity and fisheries (NCEAS 2001). In Europe, an influential scientific committee has recommended that $20-30 \%$ of the UK's fisheries zone (out to $200 \mathrm{~nm}$ ) be designated as a network of NTMPAs, and that this network should eventually be extended throughout Europe (RCEP 2004).

Calls for NTMPAs have now become embodied in international targets by the IUCN, the Vth World Parks Congress having recommended that $20-30 \%$ of the area of each marine habitat should be designated as NTMPA by 2012. Despite these calls and targets, there has been a less rapid growth in the designation of NTMPAs, Pauly et al. (2002) having estimated that only $\sim 0.01 \%$ of

\footnotetext{
${ }^{1}$ The general term 'marine biodiversity' is used to describe both structure-oriented (focus on conserving habitat, species and genetic diversity) and process-oriented (focus on conserving ecosystem functions and processes) perspectives (Jones 2001).
} 
the world's ocean area was designated as such, a figure which Jones (2006) estimates is increased to $\sim 0.04 \%$ solely by the additional designation as NTMPA in 2004 of a large proportion of the Great Barrier Reef Marine Park. Whilst more recent designations will have increased the total NTMPA area figure further, the $20-30 \%$ target clearly remains very ambitious. It is, therefore, worth considering the arguments of both proponents and opponents of such designations in detail in order to assess the prospects for achieving this target and, indeed, whether the target is itself valid.

\section{Challenges to the potential of no-take marine protected areas}

Jones (2006) and Kaiser (2005) discuss the arguments of proponents and opponents of NTMPAs on a number of grounds. There have recently been a growing number of publications that challenge the potential of NTMPAs. Whilst these are still outnumbered by the many papers discussed above that implicitly or explicitly make a case for NTMPAs, the growing number of challenges is a significant trend that undermines the previous apparent 'consensus' amongst the scientific community on the importance of NTMPAs. This section will briefly review some of the main recent challenges, recognising that they are interrelated.

Conventional fisheries management approaches more effective

It is increasingly being argued that CFMAs, such as quotas, effort reduction, partial seasonal closures and technical measures, will often be more effective than NTMPAs for sustaining fish stock yields (Shipp 2003, 2004; Steele and Beet 2003), mainly because most fish stocks migrate over a wide geographic scale and are therefore inappropriate for protection through site-specific measures such as NTMPAs. Furthermore, Shipp (2003, 2004) and Grimes and Ralston (2003) argue that CFMAs have proved to be quite effective for the majority of stocks, stressing that only a few stocks are actually considered to be overfished. Roberts et al. (2005) argue that CFMAs and NTMPAs are complementary, and that one cannot be effective without the other as both have their limitations. Similarly, Hilborn et al. (2004a, 2006) and Kaiser (2004, 2005) argue that NTMPAs and CFMAs will each be effective under certain conditions and that the combined use of both approaches on an integrated basis should be explored.

These arguments appear to be similar, but there is an important divergence, in that Roberts et al. (2005) are strongly advocating NTMPAs on the basis that they represent a critically important way forward for restoring ecosystems, as do many others such as Bohnsack et al. (2004), Murray et al. (1999) and Pauly et al. (2002, 2005). Whilst these authors accept the CFMAs will always have a role, they are strongly arguing that it is essential that a significant proportion of the world's seas is also set aside as NTMPAs to sustain marine ecosystems, including their component fish populations.

Hilborn et al. (2004a, 2006), Kaiser (2004, 2005), Shipp (2003, 2004) and Steele and Beet (2003), on the other hand, are primarily focussed on the potential role of NTMPAs in sustaining fish stocks. Their assessments do consider the impacts of fishing on habitats and non-target species, but their primary focus is on improving the potential of CFMAs to promote sustainable fish stock yields. Whilst these authors accept that NTMPAs will continue to have a role, particularly for highly important and sensitive habitats, they are strongly arguing that the emphasis should be on improving CFMAs to sustain wideranging fish stocks, with NTMPAs being pursued under certain conditions and on a cautious, experimental basis.

\section{Density-dependent factors}

Another key argument for NTMPAs is that wider fish populations will benefit through the spillover of adults and the export of eggs, larvae and juveniles as the density of fish populations within NTMPAs increases (e.g. Bohnsack et al. 2004; Gell and Roberts 2003a; Guénette et al. 1998; NCEAS 2001; NRC 2001; Pauly et al. 2002; RCEP 2004; Roberts et al. 2001, 2005). This 
argument is supported by modelling studies, most of which predict that NTMPAs can potentially increase yield through spillover/export, though only when populations would otherwise be overfished and mainly for species with a more sessile adult phase (Gerber et al. 2003).

There is some evidence for such densitydependent spillover from NTMPAs, for example, on coral reefs (Abesamis and Russ 2005; Abesamis et al. 2006; Ashworth and Ormond 2005), Mediterranean reefs (Goni et al. 2006) and in temperate waters (Murawski et al. 2004). Roberts et al. (2001) and Gell and Roberts (2003a) also report several examples that indicate that such spillover from NTMPAs occurs and many authors, as reviewed by Halpern (2003) and Halpern and Warner (2002), have reported increased densities of fish within NTMPAs that indicate that such spillover is likely to occur. Proponents of CFMAs argue, however, that fish yield reductions from the loss of access to NTMPAs are very unlikely to be compensated for through such spillover, therefore effort will have to be reduced if NTMPAs are designated (Grimes and Ralston 2003; Hilborn et al. 2006; Shipp 2003, 2004). Grimes and Ralston (2003) and Shipp $(2003,2004)$ point out that this argument is supported by density-dependence theory, according to which yield-per-recruit is lowest at carrying capacity, i.e. unfished populations, and that compensation at lower population levels, i.e. fished populations, produces a sustainably harvestable surplus.

Gardmark et al. (2006) expand on the issue of the confounding effect of density-dependence. They point out that models of the potential of NTMPAs have neglected density-dependence [which Gerber et al. (2003) previously identified as a priority issue for future modelling studies] and that there is empirical evidence of reduced body growth rates in protected fish stocks at higher population densities. They also point out that such evidence for NTMPA spillover benefits is lacking, citing challenges to the little empirical evidence that has been published, particularly to Roberts et al. (2001), and also cite reports of decreased or sustained yields for coral reef NTMPAs. On the basis of a model that incorporates density-dependence, they conclude that for fish populations with sedentary adults and planktonic larvae, in which larval settlement is densitydependent, a fishery area including NTMPAs will yield only the same as one managed with just CFMAs after 3 years, whilst for populations in which body growth is density-dependent, a fishery area including NTMPAs will yield less than one managed with just CFMAs. The key basis of this analysis is that density will increase not only inside the NTMPAs, but also outside the NTMPAs through larval export, and that increased fish densities will slow fish body growth. Thus the reports of density gradients associated with NTMPAs cited above would be a cause for fisheries management concern rather than evidence of NTMPA success.

Whilst their model, like all models, makes certain assumptions and is based on a limited range of parameters, the density-dependence issues it raises challenge the validity of claims that NTMPAs will increase wider fish yields through spillover/export. These challenges are supported by some of the empirical evaluations and undermined by others, and there is clearly a need for further such evaluations specifically focussed on assessing the degree/extent to which and contexts in which density-dependence undermines the wider fisheries management objectives of NTMPAs.

Rights-based approaches the way forward

It is also being increasingly argued that NTMPAs proposals do not address the root causes of the problems in fisheries management, i.e. inappropriate incentives and institutional structures that fail to control the race-to-fish, and that the emphasis should mainly be focussed on developing and implementing incentive-based approaches, such as allocating fish harvesting rights for specific areas to specific fishermen (Grafton et al. 2005; Hilborn et al. 2004a, b, 2005a, b; Steele and Hoagland 2004). Such rights may take the form of individual quotas, individual transferable quotas or territorial use rights in fisheries (Hilborn et al. 2005a). This argument is based on the view that fishermen who have been allocated such rights will have a long-term vested interest in promoting the sustainability of fish 
stocks and will individually or collectively manage them accordingly. NTMPAs, on the other hand, are considered solely as a tool for specifying the location of fishing that does not address the incentives and institutional structures responsible for overfishing. Attempts to impose NTMPAs are thus considered to be potentially detrimental, especially if they are promoted as improving yields (Hilborn et al. 2004b).

Such arguments resonate with those for the collaborative management (co-management) of fisheries, in which there is a growing interest, e.g. Domínguez-Torreiro et al. (2004), Jentoft (2005), Nielsen et al. (2004) and Wilson et al. (2003). Similarly to the argument above, it is considered that co-management approaches are essential given the evident failure of top-down approaches (Nielsen and Vedsmand 1999; Wilson 2002). Fisheries co-management essentially involves the state and the fishing industry work on a partnership rather than adversarial basis. As such, it is consistent with Hannesson's (2005) assessment that a combination of state control and rights-based approaches appears to be preferable and potentially the most successful for fisheries management. Some environmentalists also support rights-based fisheries management, arguing that they are both institutionally and environmentally sustainable in that they protect fish stocks, habitats and the communities that depend on them (Fujita and Bonzon 2005). Swan and Gréboval (2005), however, report several case studies that reveal that such approaches can still result in overfishing, especially in the face of uncertainty and conflicts, and that success depends on addressing allocation dilemmas from both a human and ecosystem perspective. They also stress that regulating access and dealing with displaced fishermen are particularly important problems that must be overcome, and that the race-to-fish can become a race-for-rights, which brings its own problems.

These problems aside, it is clear that there is considerable support for rights-based approaches to fisheries management, through which more management responsibilities would be devolved to fishermen. Proponents of NTMPAs, on the other hand, accept that such designations may not initially be supported by fishermen, therefore they may need to be imposed and strictly enforced, at least in the early stages before any wider stock fish stock benefits are realised (Roberts et al. 2005), though Hilborn et al. (2004b) argue that this is as unlikely to work as the attempted imposition of CFMAs has proved to be. Whether NTMPAs and rights-based approaches might eventually be combined is highly debatable. Fishermen may further develop the use of partially closed areas, where certain gear restrictions and/or closed seasons are employed, as part of CFMAs, and this may eventually extend to the designation of NTMPAs, if they prove to have wider fisheries management benefits. However, the emphasis of proponents of rights-based fisheries management is on the empowerment of fishermen through property right allocations to create incentives for sustainable fish stock management rather than the pursuit of NTMPA targets, that remove fishermen's access rights. It would seem, therefore, that there is a growing divergence between those that consider NTMPAs to be the way forward and those that consider rights-based fisheries management, integrated with CFMAs, to be.

Natural refuges already exist

A key aspect of the case for NTMPAs is that former natural refuges, where fishing was not possible or feasible, are increasingly fished due to technological developments, increased general effort and the depletion of populations elsewhere, and that NTMPAs are needed to substitute the function of former natural refuges in sustaining ecosystems and fish populations (Agardy et al. 2003; Pauly et al. 2002, 2005; Roberts et al. 2005). Kaiser (2005), however, argues that large areas of the seabed actually remain unfished, and that NTMPAs will compel fishermen to seek previously unexploited areas, thereby increasing overall damage to the marine environment. The RCEP (2004, para. 5.82) consider this argument to be more an assertion, based on limited data, to justify the status quo, though it must be recognised that the related case for NTMPAs could similarly be considered to be an assertion. Kaiser's (2005) argument represents a strong counter to a key aspect of the argument in favour of NTMPAs, and 
the spatial extent of fishing activities is clearly an issue that is critical to this debate.

\section{Different storylines?}

Whilst such debates are likely to continue, if not intensify, as more NTMPAs are pursued, it remains the case that a larger number of publications are calling for such designations than are challenging them. It must, however, be recognised that this merely reflects the current majority view amongst a certain constituency of scientists who are currently publishing papers calling for NTMPAs, and that this does not necessarily mean that they are potentially a good solution, in synergy with CFMAs, for reversing both marine biodiversity and fish stock declines. Certainly, there are growing challenges to the potential of NTMPAs, as discussed above, and there is a growing divergence between those that argue that the emphasis should be on CFMAs and those that argue that it should be on NTMPAs.

A key issue underlying these divergence is the degree/extent to which CFMAs have failed and the reasons underlying such failures. Proponents of NTMPAs, such as Roberts et al. (2005), consider that one of the key reasons is that fishermen are too driven by the desire to maximise their short-term and personal gain. Therefore they have successfully undermined CFMAs by getting round or breaking fish stock conservation measures. As NTMPAs are claimed to be easier to enforce than CFMAs and will eventually need less enforcement as fishermen come to appreciate their wider fish stock enhancement benefits, the potential for fishermen to undermine them will be reduced. Opponents of NTMPAs, such as Hilborn et al. (2004a, b) and Steele and Hoagland (2004), consider that where such measures have failed, this is largely because they have been imposed on fishermen, and that imposing NTMPAs will similarly fail. Accordingly, they argue for the assignation of property rights to fish stocks and comanagement through the greater involvement of fishermen in decision-making processes.

In a related sense, proponents of NTMPAs accept that one of the reasons CFMAs have failed is that regulatory decisions have not been consis- tent with scientific advice. Roberts et al. (2005) point out that Fisheries Ministers in the European Commission have consistently set total allowable catches (TACs) $15-30 \%$ higher than the International Council for the Exploration of the Seas has advised and that this has exacerbated management difficulties. This is consistent with Shipp's (2003) argument that CFMAs could become more precautionary and effective in restoring overfished stocks if more conservative TACs were adopted, alongside improvements in stock assessments. Roberts et al. (2005) counter this in arguing that even with such precautionary TACs, CFMAs would still have high information requirements and would fail to address the wider ecosystem and genetic impacts of fishing, therefore NTMPAs are essential. Kaiser (2005), however, argues that NTMPAs are "equally prone to the same political horse trading that has neutered many current management systems," whilst Roberts et al. (2005) argue that NTMPAs have much lower information requirements than CFMAs, therefore it could be argued that they are less prone to political horse trading in relation to interpreting and implementing scientific information. Kaiser (2005), however, is essentially arguing that such trading, driven by political shorttermism, is likely to lead to fewer and smaller NTMPAs being designated, if any, in the first place. On the basis that NTMPAs will be designated alongside continued wider CFMAs, Roberts et al. (2005) argue that NTMPAs can safeguard against the setting of over-generous, risky quotas in CFMAs. Whilst there is some agreement on these issues, there is clearly a divergence between proponents of NTMPAs and CFMAs on the issues raised by political factors and scientific information requirements.

It is important to recognise that these divergent views represent different perspectives on the broad issue of the nature of the challenges posed by marine fisheries and marine biodiversity conservation and the potential of CFMAs and NTMPAs to address these. These two perspectives might be considered as contrasting 'storylines' (Hajer 1995) on this broad issue (Table 1), an assessment of which reveals that whether one or the other perspective is adopted, the arguments can be considered logical, but the two 


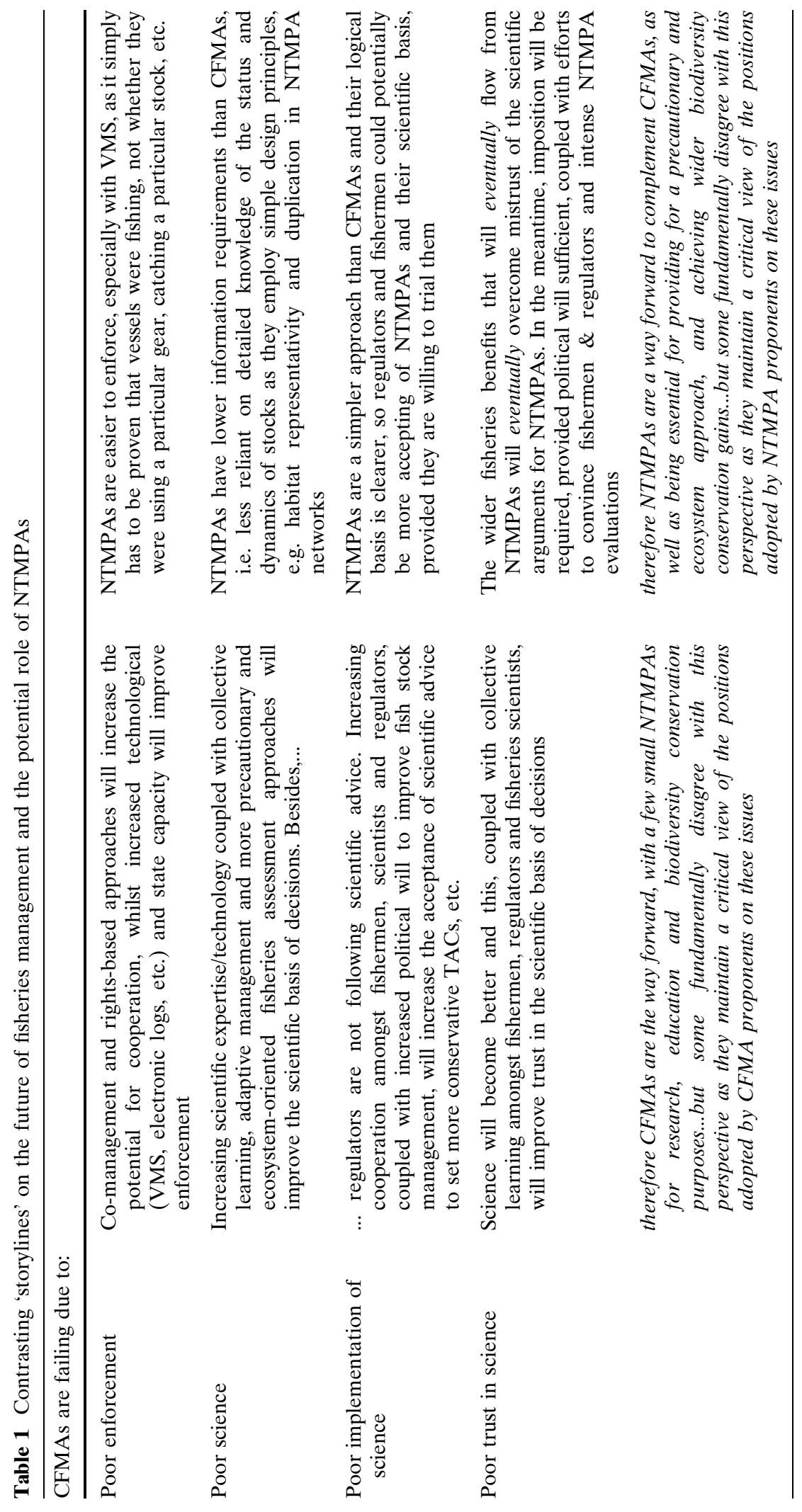


perspectives will reach very different conclusions. This is arguably the pattern that has emerged from the literature on this broad issue, many publications arguing that NTMPAs are a key way forward to complement CFMAs, as they are essential for providing for a precautionary and ecosystem approach, and achieving wider biodiversity conservation gains, and a growing number of publications arguing that CFMAs are the way forward, with a few small NTMPAs for research, education and biodiversity conservation purposes. In the meantime, relevant politicians and regulators, as well as fishermen and other interested parties, are receiving conflicting 'expert' opinions.

This, of course, is not unusual as it applies to many other important environmental debates that are characterised by high scientific uncertainty, high potential environmental consequences and a high diversity of perspectives (Ravetz 1999). However, it is important that such debates, including those concerning NTMPAs, do not become bogged down by a polarisation of perspectives and regulatory confusion over the validity of these different perspectives, as this could lead to the maintenance of the status quo, whether or not this represents the best way forward. It must be recognised that scientific uncertainty is a key issue in marine ecosystems due to their complex and difficult to study nature (Jones 2001). However, Ludwig et al. (1993) have proposed that full scientific consensus concerning fisheries and marine ecosystems shall never be attained, as controlled and replicated experiments are impossible to perform in such large scale systems, and Jones (2006) reviews arguments that support this proposition in relation to NTMPAs.

Ludwig et al. (1993) also argued that scientific uncertainty is not necessarily an obstacle to conservation initiatives, and that actions should be taken on an iterative, adaptive basis which recognises scientific uncertainty, rather than delaying actions in the quest for scientific certainty. Translating such arguments into NTMPA designations in the face of objections from fishermen, to whom the economic and lifestyle losses are immediate and obvious, and confounding scientific views from proponents of CFMAs will, however, in reality be extremely problematic, as is evidenced by the very slow progress to date with NTMPA designations (Jones 2006). It seems likely that these opposing storylines will continue to be a major obstacle to further NTMPA designations.

\section{Different objectives?}

The divergences between these two storylines might, however, simply be a reflection of differing ethical perspectives, NTMPA proponents being more influenced by preservationist and ecocentric perspectives, and CFMA proponents being more influenced by the utilitarian resource conservation perspective. ${ }^{2}$ This ethical difference is arguably evidenced by the use of the term fish 'stocks' by CFMA proponents and fish 'populations' by NTMPA proponents, the former seeing commercial fish stocks essentially as a resource to be sustainably harvested, including the protection of 'essential fish habitats', the latter seeing fish populations, other marine species and the habitats that directly and indirectly support them as components of a wider ecosystem, the ecosystem and its components having non-use and ecological values. An illustration of how this ethical difference is perceived was provided in a debate in 1999 on the California Marine Protected Area Network email discussion list, in which fishermen accused scientists who were putting forward arguments for NTMPAs of being on a purely moral 'deep green' mission (Jones 2001). As such, this divergence might be considered as a basic conflict on which the potential for convergence is unlikely given that it would entail compromises between these ethical perspectives (Jones 2006).

It may also be considered as meaning that the arguments of proponents of CFMAs are valid only from a utilitarian resource conservation perspective, as they are only scientifically and ethically focussed on sustaining fish stock yields. This is consistent with the view that society's relation to the seas is largely defined in utilitarian terms of the resources it provides (Cole-King 1995), particularly fish stocks. Proponents of NTMPAs, on the other hand, have extended

\footnotetext{
2 See Callicot (1991) for an outline of these ethical perspectives in the context of fisheries management.
} 
their scientific and ethical concerns from fish stocks to wider fish populations, other marine species and the habitats and ecosystems that support them. As such, the arguments against NTMPAs put forward by proponents of CFMAs are only valid in relation to the fisheries conservation objectives of such designations, i.e. such arguments do not extend to or undermine the non-target species, habitat and ecosystem conservation objectives of NTMPAs. This represents an important caveat to the challenges to NTMPAs such as those reviewed above. In a related sense, it has been questioned whether it is valid and necessary to 'sell' the fisheries resource management benefits of NTMPAs (Jones 2006), i.e. terrestrial conservationists do not have to convince hunters that protected areas will produce a surplus of wildlife that spills over and supports surrounding hunting communities, so why should we not think of NTMPAs "in the same way we think about terrestrial parks-simply as secure havens for biodiversity" (Kareiva 2003).

Arguments concerning the cultural symbolic value of NTMPAs as set-aside areas (Jones 2001), the existence and future value of NTMPAs (Bohnsack et al. 2004) and the need to temper CFMAs with increased ethical concern for the fragility of natural ecosystems (Caddy and Seijo 2005) are also valid in this respect. Calls for NTMPAs might thus be considered as reflecting increasing scientific and societal concerns about the health of marine ecosystems, including but not confined to their constituent fish populations. Such calls are arguably significantly influenced by a desire to extend the preservationist and ecocentric ethic to our seas rather than continuing the domination of the utilitarian resource conservation ethic.

No-take marine protected areas have been promoted as a win-win approach, in that they can confer benefits for both marine biodiversity and fish stock conservation (Gell and Roberts 2003b). However, Ballantine (2002) argues that the primary aim of NTMPAs is to conserve or restore marine biodiversity and that whilst it is likely that benefits will also be provided for fisheries, such benefits should be regarded as bonuses. Similarly, Halpern et al. (2004) argue that NTMPAs "need not, and perhaps should not, be designed with fisheries management as a primary goal." In keeping with these views, it is increasingly accepted that the primary goal of NTMPAs is to conserve marine biodiversity, with fisheries management being a secondary objective. The arguments against NTMPAs based on their lack of fisheries management benefits must accordingly be considered as only applying to the secondary resource conservation objectives of such designations and not to the primary marine biodiversity conservation objectives.

\section{Different science?}

A key basis of the arguments for NTMPAs is that they are essential if we are to adopt an ecosystem approach to the management of our seas (Botsford et al. 1997; Murray et al. 1999; Palumbi 2003; Pauly et al. 1998, 2002; Roberts 1997), recognising that fishing is having major ecosystem impacts (Pauly et al. 2005). This requires management approaches that promote wider 'ecosystem health' rather than being focussed on 'fish stock health'. Dealing with uncertainty is an important challenge if such a approaches are to be adopted, recognising the complexity of marine ecosystems, and there are different perspectives on how such uncertainty might be dealt, as the introduction by Browman and Stergiou (2005) points out and the papers in that special issue reveal. The ecosystem approach also incorporates other 'warm and fuzzy' notions besides ecosystem health, such as the health of fishing communities and the needs of future generations, and involves societal value judgements on desired outcomes and the need for related trade-offs (Quinn and Collie 2005).

Fisheries scientists are developing approaches to fisheries management that are consistent with the ecosystem approach, such as whole ecosystem modelling, including insights into the human dimension of fisheries management. Such approaches aim to provide for fisheries management to contribute towards ecosystem restoration, including provision for the involvement of stakeholders and the reduction of uncertainties in ecosystem simulation techniques (Pitcher 2005). Similarly, Quinn and Collie (2005) discuss how modern fisheries management has become more 
precautionary and how post-modern fisheries management approaches must incorporate both ecosystem and stakeholder concerns, recognising that "advancement made under the single species approach should not be abandoned but combined with new approaches in the multi-species and economic realms." Several papers in the volume introduced by Browman and Stergiou (2005) discuss how fisheries management has developed and will continue to develop towards an ecosystem approach.

However, NTMPA proponents argue that such designations, in combination with CFMAs, are an essential element of the ecosystem approach as they provide a precautionary buffer against uncertainty (Murray et al. 1999; Guénette et al. 1998; Lauck et al. 1998; Stefansson and Rosenberg 2005). Such arguments are essentially based on the view that our understanding of complex marine ecosystems will never be sufficient to enable fish populations, including their functional relationships with other ecosystem components, to be accurately assessed and modelled. Pitcher (2005) recognises that reducing uncertainty in ecosystem simulation techniques and making decisions robust against climate change will be a challenge. Arguments for NTMPAs, however, are based on the view that reducing such uncertainty to a safe degree, in keeping with the precautionary principle, is not realistic, therefore NTMPAs are essential, i.e. CFMAs alone cannot address uncertainty and wider societal concerns about the health of marine ecosystems.

The divergence between these views is consistent with the distinction between Mode 1 and Mode 2 science, the former characterised as being reductive, intra-disciplinary and applied but not societally accountable/inclusive, and the latter as holistic, trans-disciplinary and carried out in collaboration with society in the context of application, with which it co-evolves (Gibbons et al. 1994). Mode 2 science recognises that uncertainties will proliferate rather than being progressively eradicated; therefore they should be accommodated rather than feared, including new societal (not just scientific) innovations to cope with uncertainties (Nowotony et al. 2001). Criticisms of NTMPAs and support for CFMAs might thus be interpreted as implicitly resisting the shift to adopt Mode 2 science, to supplement rather than supplant Mode 1 science, that is arguably inherent in calls for NTMPAs.

\section{Conclusion}

Against a background of many calls for NTMPAs to address marine biodiversity and fish stock declines, recent challenges to the potential of such designations are reviewed. These revolve around arguments that CFMAs are more effective, density-dependent factors will lead to reduced fish stock production in and around NTMPAs, rightsbased approaches in combination with CFMAs will be more effective, and natural refuges from fishing already exist. These arguments are largely valid from a fisheries management perspective and it must be recognised that the large number of papers calling for NTMPAs to address marine biodiversity and fisheries declines merely represents a consensus amongst a certain constituency of scientists, which is validly challenged by other scientists. The arguments of proponents of NTMPAs and those of proponents of CFMAs might thus be considered as contrasting storylines, the headings of which are the same but the narratives and conclusions of which are very different (Table 1). This can fuel confusion amongst the public and decision-makers and may contribute to the maintenance of the status quo, whether or not this represents the best way forward.

It is argued that the divergences between these storylines are based on two key factors: different objectives and different science. In relation to different objectives, it is concluded that the arguments against NTMPAs based on their lack of fisheries management benefits must be considered as only applying to the secondary resource conservation objectives of such designations and not to the primary marine biodiversity conservation objectives. On this basis it is arguably counter-productive for NTMPAs to be 'sold' on a win-win basis, including their potential to deliver fisheries management benefits, as this detracts from their marine biodiversity conservation objectives and leaves such calls open to arguments that CFMAs are better able to deliver fisheries management objectives. 
In relation to different science, it is concluded that criticisms of NTMPAs and support for CFMAs might be interpreted as implicitly resisting the shift from Mode 1 (reductive, intradisciplinary and applied but not societally accountable/inclusive) to Mode 2 (holistic, transdisciplinary and carried out in collaboration with society in the context of application, with which it co-evolves) science that is arguably inherent in calls for NTMPAs. Again, it is arguably counterproductive for the potential of NTMPAs for fisheries and marine biodiversity to be assessed and 'sold' using reductive models as this perpetuates the Mode 1 'Newtonian' view that the interspecies dynamics and cause-effect relationships of marine ecosystems can be determined. Wilson (2002) argues that the quest for such certainty is one of the factors behind the failure of CFMAs.

So how can NTMPA proponents avoid this 'reductive trap' and move forward? Mode 2 science aims to accommodate both uncertainty and wider societal values and preferences, and it is argued that the case for NTMPAs should be more explicitly focussed on this potential, as this is a key strength. It is difficult, if not impossible and inappropriate, to extend the reductive approach inherent in CFMA analyses to encompass the broader ethical and scientific concerns for the health of marine ecosystems and their component populations and habitats that arguments for NTMPAs reflect. NTMPA proponents might focus on stressing that arguments against such designations and in favour of CFMAs continue to focus on the utilitarian view of the seas as a collection of resources and do not encompass such valid concerns, therefore they tell only half of the story.

\section{References}

Abesamis RA, Russ GR (2005) Density-dependent spillover from a marine reserve: long-term evidence. Ecol Appl 15(5):1798-1812

Abesamis RA, Russ GR, Alacala AC (2006) Gradients of abundance of fish across no-take marine reserve boundaries: evidence from Philippine coral reefs. Aquat Conserv 16(4):349-371

Agardy T, Bridgewater P, Crosby MP et al (2003) Dangerous targets? Unresolved issues and ideological clashes around marine protected areas. Aquat Conserv 13(4):353-367
Ashworth JS, Ormond RFG (2005) Effects of fishing pressure and trophic group across boundaries of a no-take zone. Biol Conserv 121(3):333-344

Ballantine WJ (2002) MPA perspective: MPAs improve general management, while marine reserves ensure conservation. MPA News 4(1):5. depts.washington.edu/mpanews/MPA32.htm\#Ballantine

Bohnsack JA, Ault JS, Causey B (2004) Why have no-take marine protected areas? Am Fish Soc Symp 42:185-193

Botsford LW, Castilla JC, Peterson CH (1997) The management of fisheries and marine ecosystems. Science 277:509-515

Browman HI, Stergiou KI (2005) Introduction. Mar Ecol Prog Ser 300:241-242. Theme section on the 'politics and socio-economics of ecosystem-based management of marine resources' (further 12 papers)

Caddy JF, Seijo JC (2005) This is more difficult than we thought! The responsibility of scientists, managers and stakeholders to mitigate the unsustainability of marine fisheries. Philos Trans R Soc B 360(1453):59-75

Callicot JB (1991) Conservation ethics and fishery management. Fisheries 16(2):22-28

Cole-King A (1995) Marine protected areas in Britain: a conceptual problem? Ocean Coast Manag 27(12):109-127

Domínguez-Torreiro M, Freijeiro-Álvaraz AB, IglesiasMalvido C (2004) Co-management proposals and their efficiency implications in fisheries management: the case of the grand sole fleet. Mar Policy 28(3):213-219

Fujita R, Bonzon K (2005) Rights-based fisheries management: an environmentalist perspective. Rev Fish Biol Fish 15(3):309-312

Gardmark A, Jonzen N, Mangel M (2006) Densitydependent body growth reduces the potential of marine reserves to enhance yields. J Appl Ecol 43(1):61-69

Gell FR, Roberts CM (2003a) Benefits beyond boundaries: the fishery effects of marine reserves. Trends Ecol Evol 18(9):448-455

Gell FR, Roberts CM (2003b) Marine reserves for fisheries management and conservation: a win-win strategy. El Anzuelo: Eur Newsl Fish Environ 11:4-6. www.ieep.org.uk/publications/pdfs/elanzuelo/v11english.pdf

Gerber LR, Botsford LW, Hastings A et al (2003) Population models for marine reserve design: a retrospective and prospective synthesis. Ecol Appl 13(1):S47-S64

Gibbons M, Limoges C, Nowotony H et al (1994) The new production of knowledge. Sage, London

Goni R, Quetglas A, Renones O (2006) Spillover of spiny lobsters palinurus elephas from a marine reserve to an adjoining fishery. Mar Ecol Prog Ser 308:207-219

Grafton RQ, Arnason R, Bjorndal T et al (2005) Incentive-based approaches to sustainable fisheries. Can J Fish Aquat Sci 63(3):699-710

Grimes CB, Ralston S (2003) Marine reserves: the best option for our oceans? Front Ecol Environ 1(9):496497

Guénette S, Lauck T, Clark C (1998) Marine reserves: from Beverton and Holt to the present. Rev Fish Biol Fish 8(3):251-272 
Hajer MA (1995) The politics of environmental discourse: ecological modernisation and the policy process. Calderon, Oxford, UK

Halpern B (2003) The impact of marine reserves: do reserves work and does reserve size matter? Ecol Appl 13(1):S117-S137

Halpern BS, Warner RR (2002) Marine reserves have rapid and lasting effects. Ecol Lett 5(3):361-366

Halpern BS, Gaines SD, Warner RR (2004) Confounding effects of the export of production and the displacement of fishing effort from marine reserves. Ecol Appl 14(4):1248-1256

Hannesson R (2005) Rights based fishing: use rights versus property rights to fish. Rev Fish Biol Fish 15(3):231241

Hilborn R, Punt AE, Orensanz J (2004a) Beyond bandaids in fisheries management: fixing world fisheries. Bull Mar Sci 74(3):493-507

Hilborn R, Stokes K, Maguire J et al (2004b) When can marine reserves improve fisheries management? Ocean Coast Manag 47(3/4):197-205

Hilborn R, Orensanz JM, Parma AM (2005a) Institutions, incentives and the future of fisheries. Philos Trans R Soc B 360(1453):47-57

Hilborn R, Parrish JK, Litle K (2005b) Fishing rights or fishing wrongs? Rev Fish Biol Fish 15(3):191-199

Hilborn R, Micheli F, De Leo GA (2006) Integrating marine protected areas with catch regulation. Can $\mathbf{J}$ Fish Aquat Sci 63:642-649

IUCN (1994) Guidelines for protected area management categories. IUCN, Gland, Switzerland/Cambridge, UK

Jentoft S (2005) Fisheries co-management as empowerment. Mar Policy 29(1):1-7

Jones PJS (2001) Marine protected area strategies: issues, divergences and the search for middle ground. Rev Fish Biol Fish 11(3):197-216

Jones PJS (2006) Collective action problems posed by notake zones. Mar Policy 30(2):143-156

Kaiser MJ (2004) Marine protected areas: the importance of being earnest. Aquat Conserv 14:635-638

Kaiser MJ (2005) Are marine protected areas a red herring or fisheries panacea? Can J Fish Aquat Sci 62(5):11941199

Kareiva P (2003) Marine reserves: the best option for our oceans? Front Ecol Environ 1(9):501-502

Lauck T, Clark CW, Mangel M, Munro GR (1998) Implementing the precautionary principle in fisheries management through marine reserves. Ecol Appl 8(1 Suppl.):S72-S78

Ludwig D, Hilborn R, Walters C (1993) Uncertainty, resource exploitation and conservation: lessons from history. Science 260:17-36

MCBI (Marine Conservation Biology Institute) (1998) Troubled waters: a call for action. mcbi.org/AboutUs/ TroubledWaters.pdf

Murawski S, Rago P, Fogarty M (2004) Spillover effects from temperate marine protected areas. Am Fish Soc Symp 42:167-184
Murray SN, Ambrose RF, Bohnsack JA et al (1999) Notake reserve networks: sustaining fishery populations and marine ecosystems. Fisheries 24(11):11-25

NCEAS (National Centre for Ecological Analysis and Synthesis) (2001) Scientific consensus statement on marine reserves and protected areas. JIWLP 4(1):8790 [Harvard Bluebook abbreviation: J Int'l Wildlife L \& Pol'y-or full title, whichever RFBF prefers]

NRC (National Research Council) (2001) Marine protected areas: tools for sustaining ocean ecosystems. National Academy Press, Washington

Nielsen JR, Vedsmand T (1999) User participation and institutional change in fisheries management: a viable alternative to the failures of 'top-down' driven control? Ocean Coast Manag 42:19-37

Nielsen JR, Degnbol P, Viswanathan KK et al (2004) Fisheries co-management-an institutional innovation? Lessons from South East Asia and Southern Africa. Mar Policy 28(2):151-160

Nowotony H, Scott P, Gibbons M (2001) Re-thinking science: knowledge and the public in the age of uncertainty. Polity, Cambridge

Palumbi SR (2003) Marine reserves: a tool for ecosystem management and restoration. Pew Oceans Commission, Washington

Pauly D, Christensen V, Dalsgaard J et al (1998) Fishing down marine food webs. Science 279(5352):860-863

Pauly D, Christensen V, Guénette S et al (2002) Towards sustainability in world fisheries. Nature 418(6898):689695

Pauly D, Watson R, Alder J (2005) Global trends in world fisheries: impacts on marine ecosystems and food security. Philos Trans R Soc B 360(1453):5-12

Pitcher TJ (2005) Back-to-the-future: a fresh policy initiative for fisheries and a restoration ecology for ocean ecosystems. Philos Trans R Soc B 360(1453):107-121

Quinn TJ, Collie JS (2005) Sustainability in singlespecies population models. Philos Trans R Soc B 360(1453):147-162

RCEP (Royal Commission on Environmental Pollution) (2004) Turning the tide: addressing the impact of fisheries on the marine environment. Twenty-fifth report of the RCEP, London. www.rcep.org.uk/fishreport.htm

Ravetz JR (1999) What is post-normal science? Futures 31(7):647-653

Roberts CM (1997) Ecological advice for the global fisheries crisis. Trends Ecol Evol 2(1):35-38

Roberts CM, Bohnsack JA, Gell F et al (2001) Effects of marine reserves on adjacent fisheries. Science 294(5548):1920-1923

Roberts CM, Hawkins JP, Gell FR (2005) The role of marine reserves in achieving sustainable fisheries. Philos Trans R Soc B 360(1453):123-132

Shipp RL (2003) A perspective on marine reserves as a fishery management tool. Fisheries 28(12):10-21

Shipp RL (2004) Harvest benefits: marine reserves or traditional fishery management tools. Am Fish Soc Symp 42:125-131 
Steele JH, Beet AR (2003) Marine protected areas in 'nonlinear' ecosystems. Proc R Soc Lond B Biol 270(Suppl.):S230-S233

Steele JH, Hoagland P (2004) Reply to Zeller and Russ. Fish Res 67:247-248

Stefansson G, Rosenberg AA (2005) Combining control measures for more effective management of fisheries under uncertainty: quotas, effort limitation and protected areas. Philos Trans R Soc B 360(1453):133-146

Swan J, Gréboval D (eds) (2005) Report and documentation of the international worksop 'international fisheries instruments and factors of unsustainability'. Siem Reap, Cambodia, 13-16 September 2004. FAO Fisheries Report No. 782. FAO, Rome
Willis TJ, Miller RB, Babcock RC, Tolimieri N (2003) Burdens of evidence and the benefits of marine reserves: putting Descartes before des horse? Environ Conserv 30(2):97-103

Wilson J (2002) Scientific uncertainty, complex systems and the design of common-pool institutions. In: Ostrom E, Dietz T, Dolšak N et al (eds) The drama of the commons. National Academy Press, Washington, pp 327-359

Wilson DC, Nielsen JR, Degnbol P (2003) The fisheries co-management experience: accomplishments, challenges, and prospects. Kluwer fish and fisheries series, vol 26. Kluwer Academic Publishers, Dordrecht 